\title{
Study of electroless copper plating on ABS resin surface modified by heterocyclic organosilane self-assembled film
}

\author{
H N ZHANG, J WANG, F F SUN, D LIU, H Y WANG and F WANG* \\ College of Science, Northwest A \& F University, Xinong Road No. 22, Yangling, Shaanxi 712100, China
}

MS received 23 November 2012; revised 2 April 2013

\begin{abstract}
TES) was used to fabricate self-assembled film on corona pretreated acrylonitrile-butadiene-styrene (ABS) resin surface. The self-assembled film modified ABS resin was treated by electroless copper plating. Orthogonal test was carried out to study optimal condition of the process. The surface appearance, plating rate and thickness of electroless copper films were investigated to determine the optimal time of corona-discharge, self-assembly and electroless copper plating. SEM results indicated that porous morphology appeared on ABS resin surface modified by TES self-assembled film and the surface roughness also increased. The adhesion test showed that the adhesion property between ABS resin and copper was excellent. The surface of electroless copper film had high brightness under the optimal condition of $1 \mathrm{~min}$ corona-discharge, $30 \mathrm{~min}$ self-assembly and $10 \mathrm{~min}$ electroless copper plating. The electroless-copper plating temperature was $55 \sim 60^{\circ} \mathrm{C}$ and $\mathrm{pH}$ was $13 \sim 13.5$.
\end{abstract}

Keywords. Self-assembled film; heterocyclic organosilane; electroless copper plating; orthogonal.

\section{Introduction}

Metallization of plastics is widely used today in various technological fields from the fabrication of printed circuits in microelectronics to decorative coatings in general manufacturing (Paunovic 2010). Through metallization, the specific properties of plastics such as light weight, design flexibility and low manufacturing cost are enriched by the addition of properties associated with metals. Many types of plastics can be plated, including acrylonitrile-butadiene-styrene (ABS) resin, which is among the most widely used polymer in industry because of their excellent toughness, good dimensional stability, good processability, chemical resistance and low cost (Harper and Petrie 2003). In order to improve the adhesion between ABS resin substrate and adherent metal layer, it is only possible that an appropriate etchant system is previously employed for surface conditioning. Up to date, the best method is based on a chromic acid etching, which aims to increase the surface energy and wettability of ABS resin by oxidizing its surface (Wang et al 2006). However, the presence of $\mathrm{Cr}^{6+}$ in chromic acid causes a serious environmental problem. Over the last few years, the numerous chromium-free etchant systems have been developed for electroless copper plating of polymer materials such as potassium permanganate (Lee et al 2007), $\mathrm{H}_{2} \mathrm{SO}_{4}-$ $\mathrm{MnO}_{2}$ (Li et al 2009), polymers grafting technique (Ali and Aal 2009; Garcia et al 2010), plasma modification (Charbonnier et al 2001) and laser treatment (Zhang

\footnotetext{
*Author for correspondence (wangfang4070@nwsuaf.edu.cn)
}

et al 1994). However, these systems are not as efficient as chromic acid etching to reach sufficient adhesion and complicated in the pretreatment process.

Self-assembled monolayer (SAM) is relatively of high order and has directionality. Moreover, the functional groups introduced in SAM can modify the surface property of wetting (Nuzzo et al 1992), corrosion (Laibinis and Whitesides 1992), etching (Kumar et al 1992), etc. Therefore, a chromium-free efficient process of self-assembled film of triazinedithiol silane for electroless copper plating on ABS resin surface is introduced in this paper, which is essentially based on the formation of chemical bond between ABS resin surface and the copper layer. The excellent copper layer adhesion property with ABS resin was obtained by the electroless copper plating on the self-assembled film modified ABS surface. And the electroless copper film had high brightness. Orthogonal test was carried out to study the optimal condition of the electroless copper plating on ABS resin surface. The method for ABS pretreatment is efficient, simple and environmental-friendly.

\section{Experimental}

\subsection{Materials}

Test specimens $(50 \times 20 \times 1 \mathrm{~mm})$ of ABS resin was prepared by cutting a large plate into pieces. All test plates were degreased by ultrasonic washing in absolute ethanol for $15 \mathrm{~min}$ and blow-dried in air. 6-(3-triethoxysilylpropyl)amino-1,3,5-triazine-2,4-dithiol monosodium (TES) was synthesized by the reaction between 6-(3-triethoxysi- 
<smiles>CCO[Si](CCCNc1nc([N])nc(S)n1)(OCC)OCC</smiles>

Figure 1. Structure of TES.

Table 1. Design of orthogonal test.

\begin{tabular}{|c|c|c|c|c|c|}
\hline Lev & $\begin{array}{l}\text { Corona } \\
\text { time } \\
(\mathrm{A} / \mathrm{min})\end{array}$ & $\begin{array}{c}\text { Self-assembled } \\
\text { time } \\
(\mathrm{B} / \mathrm{min})\end{array}$ & $\begin{array}{l}\text { Electroless } \\
\text { copper plating } \\
\text { time }(\mathrm{C} / \mathrm{min})\end{array}$ & $\begin{array}{c}\text { Temperature } \\
\left(\mathrm{D} /{ }^{\circ} \mathrm{C}\right)\end{array}$ & $\begin{array}{l}\mathrm{pH} \\
(\mathrm{E})\end{array}$ \\
\hline 1 & 0.5 & 5 & 5 & 50 & 12.5 \\
\hline 2 & 1 & 10 & 10 & 55 & $13 \cdot 0$ \\
\hline 3 & 2 & 30 & 15 & 60 & $13 \cdot 5$ \\
\hline 4 & 3 & 60 & 20 & 65 & $14 \cdot 0$ \\
\hline
\end{tabular}

lylpropyl)amino-1,3,5-triazine-2,4- dichloride and $\mathrm{NaSH}$ according to the method in the previous study (Wang et al 2011). The molecular structure of TES was shown in figure 1. Palladium chloride and stannous chloride crystals were stored in a vacuum dessicator prior to use. And all of the chemicals were employed as analytical reagent (AR) without further purification. Distilled water and ethanol were used as solvents.

\subsection{Preparation of TES self-assembled film on ABS surface}

TES film on ABS surface was prepared by self-assembly technology. ABS resin surface was pretreated by corona discharge using CTP-2000K. After pretreatment, hydroxyl $(-\mathrm{OH})$ or carboxyl $(-\mathrm{COOH})$ was formed on the resin surface, which was beneficial to react with silanol group $(-\mathrm{Si}-\mathrm{OH})$ of the hydrolyzed TES. TES solution was prepared by dissolving TES monomer $(3 \mathrm{mmol})$ into absolute ethanol $(95 \mathrm{~mL})$ and distilled water $(5 \mathrm{~mL})$, and aged for $24 \mathrm{~h}$ at $35{ }^{\circ} \mathrm{C}$ to allow sufficient hydrolysis of TES. Then the pretreated resin was immersed in hydrolyzed TES solution for certain time and then cured for $30 \mathrm{~min}$ at $90{ }^{\circ} \mathrm{C}$. After that the surface of sample was rinsed by distilled water and absolute ethanol.

\subsection{Electroless plating copper}

ABS resin covered by TES self-assembled film was immersed into the sensitization and activation solution (Charbonnier et al 2004; Nicolas et al 2006) containing $10 \mathrm{~g} / \mathrm{L} \mathrm{SnCl} 2 \cdot 2 \mathrm{H}_{2} \mathrm{O}$ and $0 \cdot 1 \mathrm{~g} / \mathrm{L} \mathrm{PdCl}_{2}$ for $3 \mathrm{~min}$ at $45^{\circ} \mathrm{C}$, through the immobilization of Pd catalyst for the subsequent
Table 2. Surface appearance evaluation for electroless copper plating.

\begin{tabular}{lcr}
\hline Evaluation rank & Evaluation basis & Score \\
\hline 1 & Uniform, smooth, pink & 100 \\
2 & Uniform, brick red & 75 \\
3 & Uniform, claybank & 50 \\
4 & Non-uniform, reluster, nigrities & 25 \\
5 & No plating & 0 \\
\hline
\end{tabular}
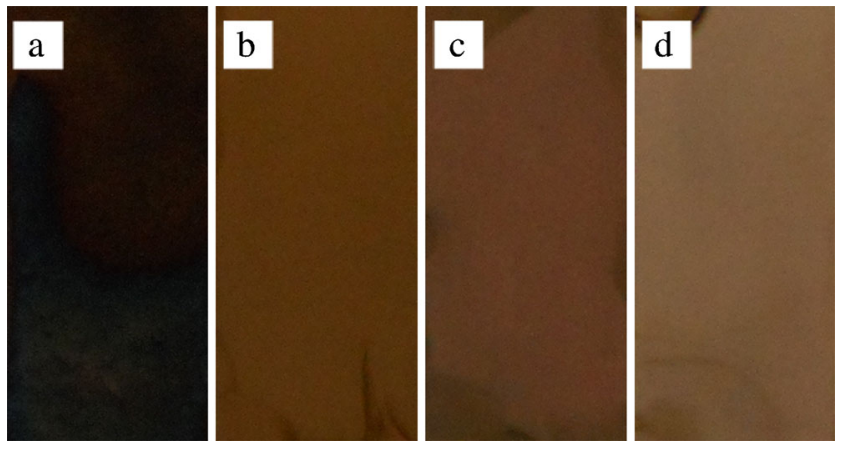

Figure 2. Photos of surface appearance evaluation of electroless copper film (a) fourth-grade; (b) third-grade; (c) second-grade and (d) first-grade.

electroless copper plating. In order to remove $\mathrm{Sn}^{2+}$ around $\mathrm{Pd}^{0}$ in colloids solution, the activated ABS resin was subsequently accelerated in an aqueous solution containing $3.7 \%$ hydrochloric acid for $30 \mathrm{~s}$ at $45{ }^{\circ} \mathrm{C}$ and then rinsed with distilled water. The surface-activated ABS resin was metallized using electroless copper plating bath containing $16 \mathrm{~g} / \mathrm{L}$ $\mathrm{CuSO}_{4} \cdot 5 \mathrm{H}_{2} \mathrm{O}, 25 \mathrm{~mL} / \mathrm{l} \mathrm{HCHO}, 25 \mathrm{~g} / \mathrm{L}$ potassium sodium tartrate and $2 \mathrm{~g} / \mathrm{L} \mathrm{NH}_{4} \mathrm{Cl}$.

\subsection{Orthogonal test}

Orthogonal test was carried out to investigate the optimal condition of pretreatment and electroless copper plating process on ABS resin surface. Corona time (A), self-assembled time (B), electroless copper plating time (C), temperature (D) and $\mathrm{pH}(\mathrm{E})$ were analysed as the main influencing parameters of the two processes and taken as factors of the orthogonal test with each factor including four levels. The orthogonal test was conducted by the orthogonal array of L16 $\left(4^{5}\right)$. Table 1 shows details of the factors and levels.

\subsection{Characterization}

2.5a Adhesion test: The adhesion property of electroless copper plating with ABS resin was evaluated by cross cut test. The single-edge cutter was used for the peeling test. Two cuts at $90^{\circ}$ from each other are formed along the sample. 

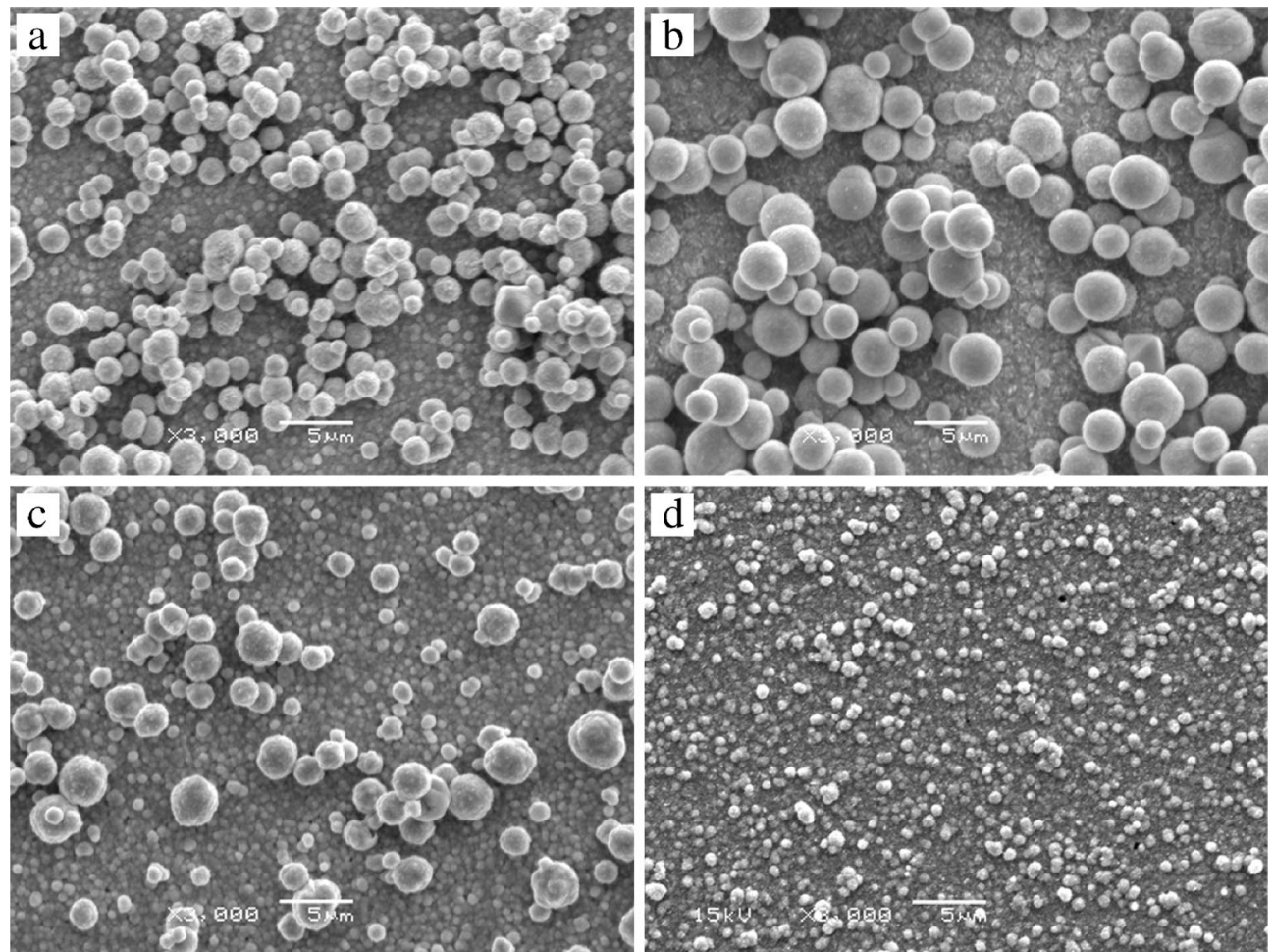

Figure 3. SEM images of surface appearance evaluation of electroless copper film (a) fourth-grade; (b) third-grade; (c) second-grade and (d) first-grade.

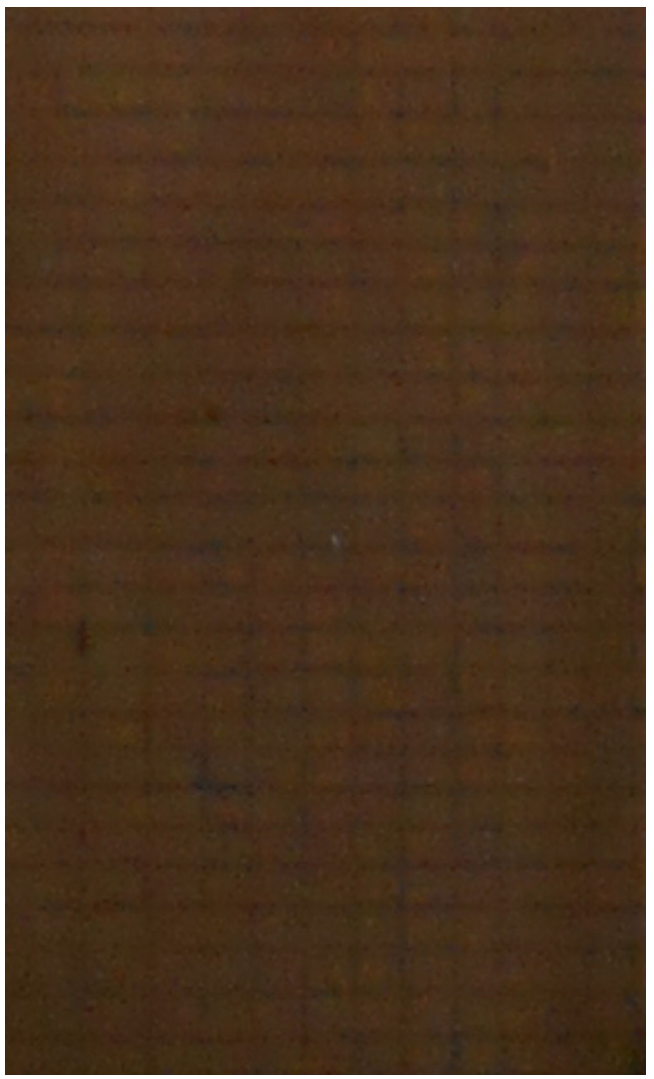

Figure 4. Adhesion test of electroless copper plating on ABS surface by ruling method. 

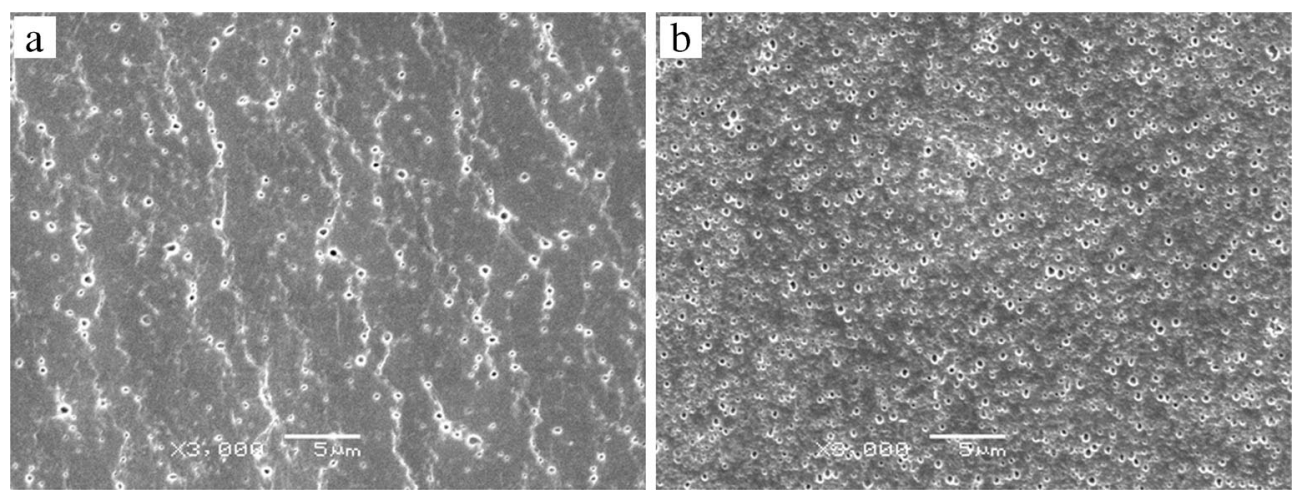

Figure 5. SEM images of ABS resin surface (a) bare ABS surface and (b) TES self-assembled film modified ABS surface.

Table 3. Orthogonal test for electroless copper plating on ABS resin surface.

\begin{tabular}{|c|c|c|c|c|c|c|c|c|c|}
\hline Test number & A & B & $\mathrm{C}$ & $\mathrm{D}$ & $\mathrm{E}$ & $\begin{array}{c}\text { Surface } \\
\text { appearance }\end{array}$ & $\begin{array}{l}\text { Thickness } \\
(\mu \mathrm{m})\end{array}$ & $\begin{array}{l}\text { Plating rate } \\
(\mu \mathrm{m} / \mathrm{min})\end{array}$ & $\begin{array}{c}\text { Comprehensive } \\
\text { score }\end{array}$ \\
\hline 1 & 1 & 1 & 1 & 1 & 1 & 0 & 0.000 & 0.000 & 0 \\
\hline 2 & 1 & 2 & 2 & 2 & 2 & 100 & 0.522 & $0 \cdot 052$ & 0.628 \\
\hline 3 & 1 & 3 & 3 & 3 & 3 & 75 & $2 \cdot 028$ & $0 \cdot 135$ & 0.785 \\
\hline 4 & 1 & 4 & 4 & 4 & 4 & 50 & $2 \cdot 794$ & $0 \cdot 140$ & 0.755 \\
\hline 5 & 2 & 1 & 2 & 3 & 4 & 75 & $1 \cdot 911$ & $0 \cdot 191$ & $0 \cdot 845$ \\
\hline 6 & 2 & 2 & 1 & 4 & 3 & 100 & 0.695 & $0 \cdot 139$ & 0.762 \\
\hline 7 & 2 & 3 & 4 & 1 & 2 & 100 & 0.706 & $0 \cdot 035$ & 0.627 \\
\hline 8 & 2 & 4 & 3 & 2 & 1 & 100 & $0 \cdot 612$ & 0.041 & 0.624 \\
\hline 9 & 3 & 1 & 3 & 4 & 2 & 50 & $1 \cdot 507$ & $0 \cdot 100$ & $0 \cdot 554$ \\
\hline 10 & 3 & 2 & 4 & 3 & 1 & 50 & $1 \cdot 196$ & $0 \cdot 060$ & 0.466 \\
\hline 11 & 3 & 3 & 1 & 2 & 4 & 100 & 0.732 & $0 \cdot 147$ & 0.777 \\
\hline 12 & 3 & 4 & 2 & 1 & 3 & 100 & 0.702 & 0.070 & 0.672 \\
\hline 13 & 4 & 1 & 4 & 2 & 3 & 75 & $2 \cdot 171$ & $0 \cdot 109$ & 0.768 \\
\hline 14 & 4 & 2 & 3 & 1 & 4 & 75 & $1 \cdot 583$ & $0 \cdot 106$ & 0.696 \\
\hline 15 & 4 & 3 & 2 & 4 & 1 & 75 & 0.669 & 0.067 & 0.54 \\
\hline 16 & 4 & 4 & 1 & 3 & 2 & 75 & 0.493 & $0 \cdot 109$ & 0.574 \\
\hline k1 & 0.542 & $0 \cdot 542$ & 0.528 & 0.499 & 0.408 & $\mathrm{k} 2$ & 0.715 & 0.638 & 0.671 \\
\hline 0.699 & $0 \cdot 596$ & $\mathrm{k} 3$ & $0 \cdot 617$ & 0.682 & 0.665 & 0.667 & 0.747 & k4 & 0.644 \\
\hline 0.656 & 0.654 & 0.653 & 0.768 & Range R & $0 \cdot 173$ & $0 \cdot 140$ & $0 \cdot 143$ & $0 \cdot 200$ & $0 \cdot 360$ \\
\hline
\end{tabular}

Then, the sample is brushed and an adhesive tape is used to remove the coating.

2.5b Surface appearance: The surface appearance of electroless copper film is observed. And the standard of evaluation is presented in table 2. The photos and images of SEM are shown in figure 2((a) fourth-grade; (b) third-grade; (c) second-grade; (d) first-grade) and figure 3((a) fourthgrade; (b) third-grade; (c) second-grade; (d) first-grade), respectively.

From SEM images of the surface appearance evaluation of electroless copper film, it is known that higher the evaluation grade, smaller and denser the copper particles are. 2.5c Thickness and plating rate of copper film: The thickness and plating rate were calculated by change in weight of ABS resin surface after the metallization process, according to the following equations, respectively

$$
\begin{aligned}
& a=\frac{\left(m_{2}-m_{1}\right) \times 10^{4}}{s \times \rho}, \\
& v=\frac{\left(m_{2}-m_{1}\right) \times 10^{4}}{s \times \rho \times t},
\end{aligned}
$$

where $m_{1}$ and $m_{2}$ represent the weight of blank and copper film plated ABS resin, respectively. $\rho=8.96 \mathrm{~g} / \mathrm{cm}^{3}, s$ the area of plating and $t$ the time of electroless copper plating. 


\section{Results and discussion}

The adhesion test (figure 4) showed good adhesion property between ABS resins modified by TES self-assembled film and electroless copper film under all the conditions. SEM image indicated that the porous morphology appeared on TES film modified ABS surface, and the surface roughness increased which could improve the adhesion strength between ABS surface and electroless copper film as shown in figure 5((a) bare ABS surface; (b) TES self-assembled film modified ABS surface). Meanwhile, formation of $\mathrm{Cu}-\mathrm{S}$ chemical bond is essential to increase the adhesion strength between copper and ABS resin. As shown above, the adhesion property does not play an important role in all experimental indices and the result owing to all the factors almost have no effect on the adhesion property. So, the experimental indices were the surface appearance, plating rate and thickness.

The experimental indices (surface appearance, plating rate and thickness) of the orthogonal test were transformed into their index memberships and the formula is as below

Index membership $=\frac{\text { Index value }- \text { index minimum }}{\text { Index maximum }- \text { index minimum }}$.

According to practical experience requirement, the importance of each index is different and every index was assigned to different weights. Assume that the full score is 1 , then the weight of surface appearance is $1 / 2$, plating rate is $1 / 4$ and the thickness is $1 / 4$, respectively. Therefore, every experimental comprehensive score can be calculated by the following equation (Chen et al 2008):

$$
\begin{aligned}
\text { Comprehensive score } & =\text { surface appearance } \times \frac{1}{2} \\
& + \text { plating rate } \times \frac{1}{4}+\text { thickness } \times \frac{1}{4} .
\end{aligned}
$$

Table 3 shows detailed scheme and the results of orthogonal test for the electroless copper plating on ABS resin surface.

$\mathrm{k} 1, \mathrm{k} 2, \mathrm{k} 3$ and $\mathrm{k} 4$ are average values of comprehensive scores of corresponding level for every factor. Range $\mathrm{R}$ means the degree of dispersion. From range $R$, it can be seen that the action sequence of the five factors on the surface appearance, thickness and plating rate of the electroless copper film on ABS resin surface is $\mathrm{E}>\mathrm{D}>\mathrm{A}>\mathrm{C}>\mathrm{B}$. It means that $\mathrm{pH}$ is the most influencing factor in all the indices. The temperature comes second and effect of corona discharge time, self-assembled time and electroless copper plating time on copper film are similar. $\mathrm{A}_{2} \mathrm{~B}_{3} \mathrm{C}_{2} \mathrm{D}_{2} \mathrm{E}_{4}$ is the best combination for improving overall quality of the plating. The experimental condition for the best combination is as follows. The corona discharge time, selfassembled time and electroless copper plating time are 1,30 and $10 \mathrm{~min}$, respectively. The bath temperature for

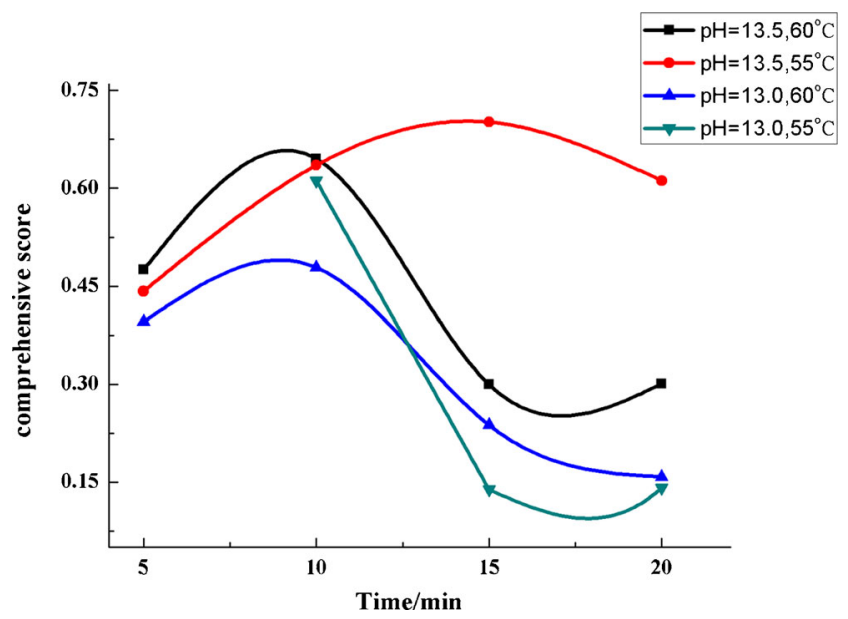

Figure 6. Effect of $\mathrm{pH}$, temperature and electroless copper plating time on comprehensive score.

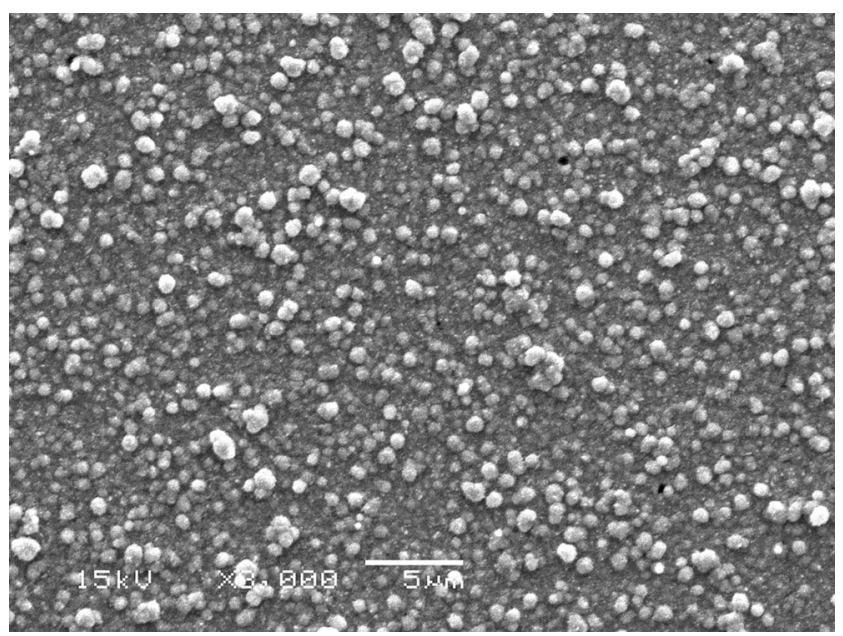

Figure 7. SEM image of electroless copper plating film on ABS resin surface.

electroless copper plating is $55{ }^{\circ} \mathrm{C}$, and $\mathrm{pH}$ is controlled at $13 \cdot 5$.

In order to verify the above result, electroless copper plating process was carried out. The conditions of $\mathrm{pH}$ (13 and 13.5), temperature $\left(55\right.$ and $\left.60{ }^{\circ} \mathrm{C}\right)$ and electroless copper plating time $(5,10,15$ and $20 \mathrm{~min})$ were set to undertake further experiments. The effect of $\mathrm{pH}$, temperature and electroless copper plating time on the comprehensive score is shown in figure 6 . The comprehensive score increased when time prolonged to $10 \mathrm{~min}$ and then decreased, which was attributed to the poorer surface appearance with the increasing of copper plating. According to the above (4), the ratio of surface appearance is $50 \%$ in the calculation of comprehensive score. Therefore, comprehensive score decreased when the copper plating time exceeded $10 \mathrm{~min}$. When $\mathrm{pH}$, temperature and electroless copper plating time were controlled at $13 \sim 13.5,55 \sim 60{ }^{\circ} \mathrm{C}$ and $10 \mathrm{~min}$, the optimal conditions for electroless copper plating could 
be obtained. Figure 7 is SEM image of electroless copper plating film on ABS resin surface under such conditions. As can be seen, the electroless copper film covered on $\mathrm{ABS}$ resin surface is the most uniform and dense at the condition.

\section{Conclusions}

By orthogonal test, the optimal condition for electroless copper plating on TES self-assembled film modified ABS resin surface was studied. The bright coating on ABS resin surface and good adhesion property between ABS resin and copper plating were obtained under the condition of $1 \mathrm{~min}$ corona discharge time, 30 min self-assembled time, 10 min electroless copper plating time, temperature of $55 \sim 60{ }^{\circ} \mathrm{C}$ and $\mathrm{pH}$ of $13 \sim 13 \cdot 5$. The plating rate and thickness are satisfied. It is expected that this method could be applied to other polymer substrates with different shapes.

\section{Acknowledgments}

The authors gratefully acknowledge the project supported by the National Natural Science Foundation of China (Grant No. 21203152) and Undergraduate Scientific and Technological Innovation Project (No. 1201210712133).

\section{References}

Ali A E H and Aal A A 2009 Polym. Adv. Technol. 20729

Charbonnier M, Romand M, Harry E and Alami M $2001 \mathrm{~J}$. Appl. Electrochem. $\mathbf{3 1} 57$

Charbonnier M, Goepfert Y, Romand M and Leonard D $2004 \mathrm{~J}$. Adhesion 801103

Chen H Y, Zhu Y L and Li C Q 2008 Mater. Res. Appl. 2261

Garcia A, Berthelot T, Viel P, Mesnage A, Roussel S and Palacin S 2010 ACS Appl. Mater. Inter. 21177

Harper C A and Petrie E M 2003 Plastics Materials and Processes: A Concise Encyclopedia (New York: John wiley \& sons. Inc.)

Kumar A, Biebuyck H A, Abbott N L and Whitesides G M 1992 J. Am. Chem. Soc. 1149188

Laibinis P E and Whitesides G M 1992 J. Am. Chem. Soc. 1149022

Lee S, Park S S and Lee H K 2007 Macromol. Symp. 249-250 586

Li Z, Li N, Yin L, He Y and Wang Z 2009 Electrochem. Solid St. 12 92

Nicolas D D, Pascu M, Vasile C and Poncin E F 2006 Surf. Coat. Technol. 2004257

Nuzzo R G, Dubois L H and Allara D L 1992 J. Am. Chem. Soc. 112558

Paunovic M 2010 Modern Electroplating Fifth edition 433 (New York: John wiley \& sons. Inc.)

Wang F, Li Y N, Wang Y B and Cao Z 2011 Nanoscale Res. Lett. 6 483

Wang G X, Li N, Hu H L and Yu Y C 2006 Appl. Surf. Sci. 253480

Zhang J Y, Esrom H, Kogelschatz U and Emig G 1994 J. Adhes. Sci. Technol. 81179 